\title{
Mechanical assessment of tripled hamstring tendon graft when using suspensory fixation for cruciate ligament reconstruction
}

\author{
I. Geethan ${ }^{1^{*}}$ D, K. Santhosh Sahanand ${ }^{2}$, P. R. Ashwin Vijay ${ }^{2}$ and David V. Rajan ${ }^{2}$
}

\begin{abstract}
Background: Tripling semitendinosus tendon for $A C L$ graft preparation facilitates creation of longer and thicker grafts. Our objective was to evaluate the mechanical difference between tripled tendon grafts, prepared by three methods, by comparing with quadrupled tendon graft.

Methods: Bovine hind-foot hoof extensors were allocated to four groups. Group I had quadrupled graft construct. Tripled graft constructs were prepared by passing the tendon to the Endobutton CL loop and stitching the third strand to (i) the loop (in Group II) or (ii) to one strand(in Group III) or (iii)to loop and both tendon strands (in Group IV). The constructs were preloaded from 10 to $50 \mathrm{~N}$ at $0.1 \mathrm{~Hz}$ for 10 cycles, followed by 1000 cycles of sinusoidal loading between 50 and $250 \mathrm{~N}$ at a frequency of $0.5 \mathrm{~Hz}$. The specimens were then subjected to load to failure test at the rate of $50 \mathrm{~mm} / \mathrm{min}$. Displacement with cyclic loading, load at failure and the mode of failure were noted.

Results: The load at failure was $957 \pm 23.30 \mathrm{~N}$ (Mean \pm Standard Deviation) in Group I, $590.8 \pm 24.40 \mathrm{~N}$ in Group II, 682. $6 \pm 59.28 \mathrm{~N}$ in Group III and $963.4 \pm 21.72 \mathrm{~N}$ in Group IV. The displacement with cyclic loading was $1.13 \pm 0.11 \mathrm{~mm}$ in Group I, $4.908 \pm 0.55 \mathrm{~mm}$ in Group II, $1.822 \pm 0.55 \mathrm{~mm}$ in Group III and 1. $126 \pm .018 \mathrm{~mm}$ in Group IV. There was no significant difference between the Groups I and IV with respect to the load at failure and displacement $(p>0.05)$. The values were significantly different in Group II and Group III ( $p<0.01$ ), when compared to groups I and IV.

Conclusions: Tripled grafts have mechanical properties equivalent to quadrupled grafts only when the three strands are sutured together. Caution may be warranted when using suspensory fixation device with tripled tendons and the third strand must be securely attached to the loop of fixation device and to the other two strands.
\end{abstract}

Keywords: Tripled hamstring tendon, Cruciate ligament reconstruction, Mechanical assessment, Suspensory fixation

\section{Background}

Anterior Cruciate Ligament (ACL) Reconstruction is the standard of care for patients who experience instability due to ruptured ACL. Semitendinosous and gracilis tendon has been one of the preferred graft choices and suspensory fixation devices like Endobutton CL (Smith \& Nephew Inc., Andover, Massachusetts) has gained popularity as fixation device (Chechik et al. 2013). Traditionally, hamstring tendons have been used as four strand grafts, either as doubled semitendinosous and gracilis tendons (Ferretti et al. 2011) or as quadrupled

\footnotetext{
*Correspondence: igeethan@gmail.com

${ }^{1}$ Arthroscopy Centre, Trichy, GastroCare Hospital, 11th Cross East, Thillai

Nagar, Thiruchirappalli, Tamil Nadu, India

Full list of author information is available at the end of the article
}

semitendinosous tendon (Streich et al. 2013) graft. Subsequently, semitendinosous tendon has been used in triplicate (Chambat et al. 2013; Vinagre et al. 2017; Zysk et al. 2000). Tripled tendon is longer than quadrupled tendon, and is thicker than a doubled tendon. While performing double bundle ACL reconstruction, only one tendon is available for each bundle and tripled grafts will result in grafts of good thickness without compromising on length. Tripling semitendinosous tendon allows preparation of five strand graft, a useful technique to increase graft diameter (Krishna et al. 2018). Thicker grafts are associated with lower meniscal stress, decreased joint laxity, and less articular cartilage contact stress (Westermann et al. 2013). The exact graft diameter needed to avoid failures is not absolutely clear but recent studies suggest than even 
increases of $0.5 \mathrm{~mm}$ up to a graft size of $10 \mathrm{~mm}$ are beneficial for the patient, by reducing risk of failure (Magnussen et al. 2012; Snaebjörnsson et al. 2017) and improving function (Mariscalco et al. 2013). While performing single bundle ACL reconstruction, the use of tripled tendons will result in grafts of sufficient length and diameter, potentially sparing gracilis tendon and limiting graft side morbidity (Gobbi 2010). Tripled tendon consists of a doubled portion of tendon, with another strand, the central strand sutured to either the loop of suspensory device or the other strands (Figs. 1, 2 and 3). Failure to suitably incorporate the central strand may result in weaker graft construct. Since suture fixation is an inferior form of fixation, the biomechanical strength of a three strand graft attached to a suspensory fixation device is equivocal (Snow et al. 2012). Moreover, different methods of tripling the tendon graft has been described in literature (Krishna et al. 2018; Lee 2013; Snow et al. 2012; Vinagre et al. 2017; Zysk et al. 2000).

The purpose of this study was to compare the mechanical properties of three different methods of preparing tripled tendon grafts when using suspensory fixation device, comparing with quadrupled tendon graft. Our hypothesis was that tripled tendon grafts prepared by different methods will have variable load to failure and displacement properties when compared to quadrupled tendon grafts of same diameter.

\section{Methods}

This is a controlled laboratory study. Bovine hind limb hoof extensor tendons were obtained from local slaughter house and used within an hour. Tendons were not frozen or thawed. Any tendon showing gross appearance of injury was excluded. All tendons that were macroscopically normal in appearance were included. The tendons were cleared of soft tissues using blunt edge of surgical knife and sized. The tendons that were minimum $320 \mathrm{~mm}$ long where allocated to Group I, and those tendons that were minimum $250 \mathrm{~mm}$ long were randomly allocated to three other groups by simple randomisation. Endobutton CL fixation button with $20 \mathrm{~mm}$
Continuous Loop Suture (Smith \& Nephew Inc., Andover, Massachusetts) was used in all samples.

\section{Placement of whipstitch}

In all groups whipstitches were placed using a No 2 Ethibond (Ethicon, Somerville, NJ) in the standard fashion (Fig. 4) and were tightened by a strong sustained pull.

\section{Group I}

The tendon was cut into two halves of $160 \mathrm{~mm}$ each. All four ends were individually whip-stitched using a No 2 Ethibond as described previously. Both strands were passed through the continuous loop of an Endobutton CL (Smith \& Nephew Inc., Andover, Massachusetts) to create a quadrupled graft.

\section{Group II}

The graft was prepared as described by Snow et al. (Snow et al. 2012). Briefly, the tendon was cut to be 240 $\mathrm{mm}$ long and the two ends of the tendon were whip-stitched as described previously. The tendon was measured and marked to identify three equal segments. One third of the tendon was passed through the Endobutton CL loop and the remaining two thirds was folded onto itself and the free end with whip stitch was secured to the Endobutton CL loop with a surgical knot consisting of four square knots. Luggage tag stitch was placed on the folded end to facilitate graft holding (Fig. 1).

\section{Group III}

The tendon was cut to be $240 \mathrm{~mm}$ and whip stitch was placed one end of the tendon. The whip stitched end of the tendon was passed through the $\mathrm{CL}$ loop. The remaining portion of the tendon was folded as in Group II and the free end was sutured onto one limb of the tendon in the loop region (Fig. 2).

\section{Group IV}

Graft was prepared as in Group II and, additionally, all three strands were sutured together (Fig. 3).

All grafts were $80 \mathrm{~mm}$ long. Their diameter was measured using a graft sizer (Smith \& Nephew Inc.,

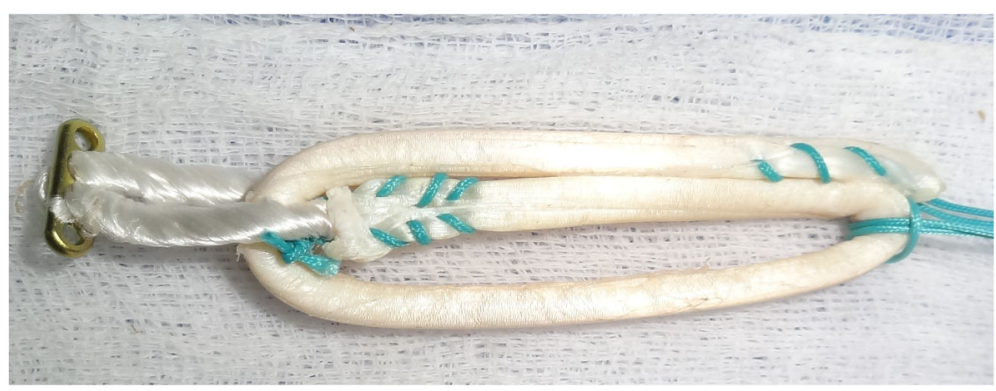

Fig. 1 Tripled graft configuration in Group II 


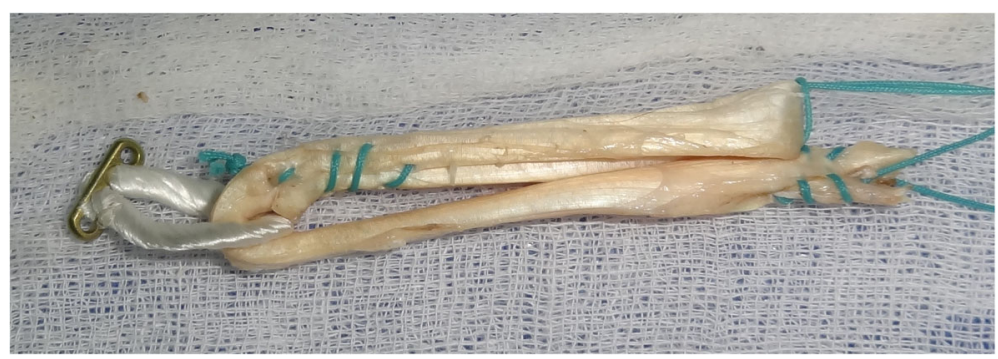

Fig. 2 Tripled graft configuration in Group III

Andover, Massachusetts). Only those grafts that were 8 $\mathrm{mm}$ in diameter were chosen for this study. Any sample that was not confirming to these standards was discarded. Five samples were included in each group.

The specimens were mounted on Material Testing Machine (Instron 6025, Instron Systems, Norwood, Massachusetts). The system consisted of vacuum assisted vices. The button was suspended from the upper vice (to simulate cortical fixation in femur) and the whip-stitched portion of graft was gripped in the lower vice. All strands were evenly gripped in the lower vice (Fig. 5).

The mechanical testing was performed as described by Petre et al. (Petre et al. 2013). The constructs were preloaded from 10 to $50 \mathrm{~N}$ at $0.1 \mathrm{~Hz}$ for 10 cycles, followed by 1000 cycles of sinusoidal loading between 50 and $250 \mathrm{~N}$ at a frequency of $0.5 \mathrm{~Hz}$. After cyclic loading the construct grafts were further displaced at $50 \mathrm{~mm} /$ Min until failure. Data were recorded by Instron wave matrix software. The ultimate failure load was recorded by the software at graft slippage or tendon rupture. The displacement after cyclical loading and ultimate load at failure were recorded by the Instron software; site and mechanism of failure were noted by inspection of grafts after mechanical testing. $T$ test was used to assess the statistical significance of the difference between the means.

\section{Results}

All samples survived cyclical loading. Group II had the highest displacement under cyclic loading $(4.91 \pm 0.49$ $\mathrm{mm})$. The displacement in the other three groups was $1.13 \pm 0.11 \mathrm{~mm}$ in Group I, $1.822 \pm 0.55 \mathrm{~mm}$ in Group III and $1.126 \pm .018 \mathrm{~mm}$ in Group IV. The displacement with cyclic loading was significantly more in Group II and Group III $(p<0.01)$. The highest ultimate load at failure $(957 \pm 23.30 \mathrm{~N})$ was noted in quadrupled tendon (Group I). The lowest load to failure was seen in Group II (590.8 $\pm 26.55 \mathrm{~N}$ ). The load to failure values in the other two groups were $682.6 \pm 59.28 \mathrm{~N}$ in Group III and 963.4 \pm $21.72 \mathrm{~N}$ in Group IV. The difference in the load at failure was not significant between groups I and IV whereas the groups II and III had statistically significant lesser load to failure than Group I $(\mathrm{p}<0.01)$. All samples in Groups I and IV failed by rupture of tendon near the lower grip (Fig. 6). Samples in Group II failed by pull through of the whipstitch in the central tendon (Fig. 7), while the samples in Group III failed by slippage of graft around the polyester loop of Endobutton CL and consequent asymmetric loading and rupture of single strand of graft (Fig. 8). These results, as well as the graft diameter, length, mode of failure of all the samples are represented in Table 1. Statistical significance for ultimate failure load and displacement after cyclic loading are presented in Table 2.

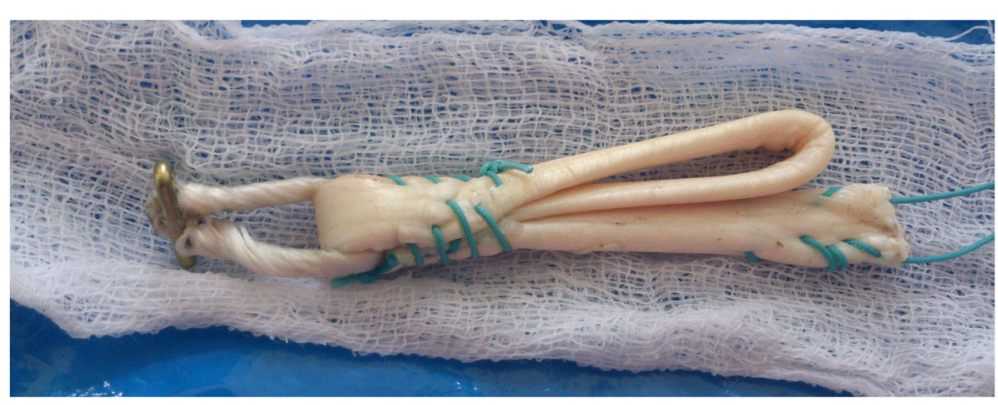

Fig. 3 Tripled graft configuration in Group IV 


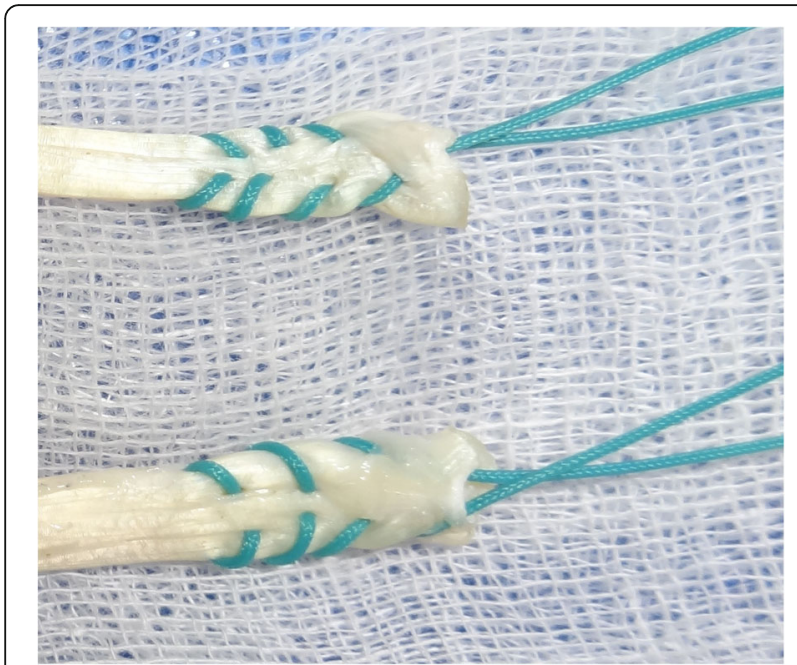

Fig. 4 Whipstitch

\section{Discussion}

The principal finding of our study is that the tripled tendon grafts have significantly different mechanical properties depending the method of graft preparation. Grafts prepared by suturing three limbs of graft together have equivalent load to failure properties as quadrupled grafts. However, the two other tripled graft constructs tested in on our study had lower load to failure.

Early rehabilitation and ambulation phases after ACL reconstruction entails loads of about 303 to 590 N (Morrison 1970; Shelburne and Pandy 1998, 2002; Shelburne et al. 2004). Of the three tripled graft constructs, groups III and IV had failure loads higher than this value in all the samples.

Cyclic displacement has an effect on a graft's ability to heal and the long term outcome of graft function. It has been reported that $3.0 \mathrm{~mm}$ or more of side-to-side difference in anterior tibial translation, as measured by KT-
1000 arthrometer testing, signifies an ACL failure in nearly all instances (Daniel et al. 1994; Daniel et al. 1985). We measured the displacement with 1000 cycles of loading between $50 \mathrm{~N}$ and $250 \mathrm{~N}$ following 10 cycles of preloading between $10 \mathrm{~N}$ and $50 \mathrm{~N}$. This testing is expected to reproduce the forces on knees following $\mathrm{ACL}$ reconstruction, and has been used on previous studies on properties of ACL fixation devices (Petre et al. 2013). Except Group II, other groups had displacement less than $3 \mathrm{~mm}$.

Among the three tripled constructs, one construct, Group II, has been studied earlier. Snow et al. studied the tensile strength and yield load of tripled grafts prepared by securing central tendon to Endobutton loop (Group II in our study) and compared it to doubled grafts (Snow et al. 2012). All samples in their study failed secondary to graft slippage at the tendon screw interface and the authors concluded that there was no mechanical difference in the overall properties between a double tendon and a tripled tendon graft when used in association with suspensory fixation. We noted that the whipstitch placed in the central tendon is pulled out, leading to failure. The difference in modes of failure might due to different tendons used for testing and different test constructs. Flexor tendons, used in the earlier study, were inherently larger than human hamstring tendons (Snow et al. 2012). We used hind limb hoof extensor tendons rather than flexor tendon. Our choice of tendon was guided by the work done by Donahue et al. The authors had compared bovine hoof extensor tendons with human semitendinosous and gracilis grafts and reported that there was no significant difference in the viscoelastic, structural and mechanical behaviour between the two tendons (Donahue et al. 2001). Further, Snow et al. used interference screw to fix the distal end of tendon in a foam block. Hence all the constructs failed at loads consistent with yield load values for

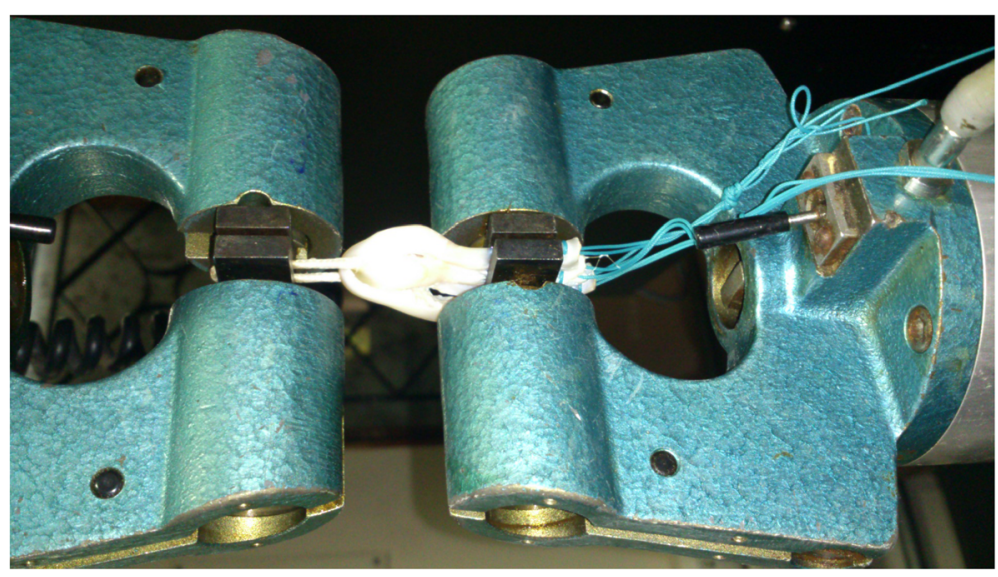

Fig. 5 Quadrupled graft construct in test assembly 


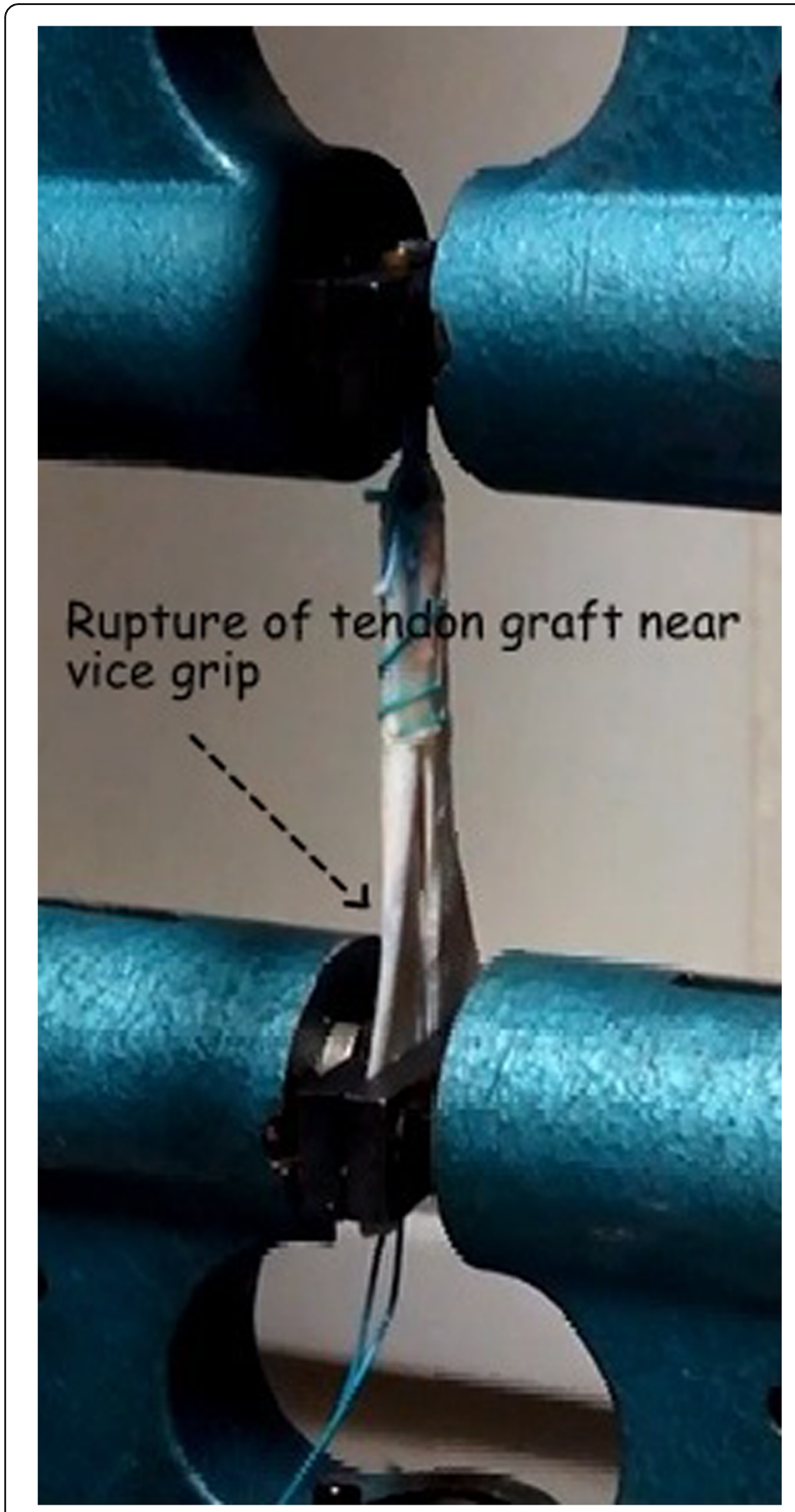

Fig. 6 Failure in Group IV, rupture of tendon near the lower vice grip

interference screw fixation. We gripped the distal end of tendon in the mechanical vice grip of the testing device (Fig. 5) to isolate mechanical properties of graft-Endobutton construct from interference screw fixation. However, in second part of the study, Snow et al. noted notable cyclic elongation occurred in the third limb of tendon (Snow et al. 2012). This finding concurs with the mode of failure noted in our testing. While Snow et al. used Fibrewire or Ultrabraid to stitch the central tendon to the loop of Endobutton, we have used Ethibond. This is unlikely to affect the outcome of this study as all the failures occurred due to pull out of whipstitch from the central tendon rather than by snapping Ethibond thread.

The other two tripled graft constructs tested in our study has not been studied earlier, though they are

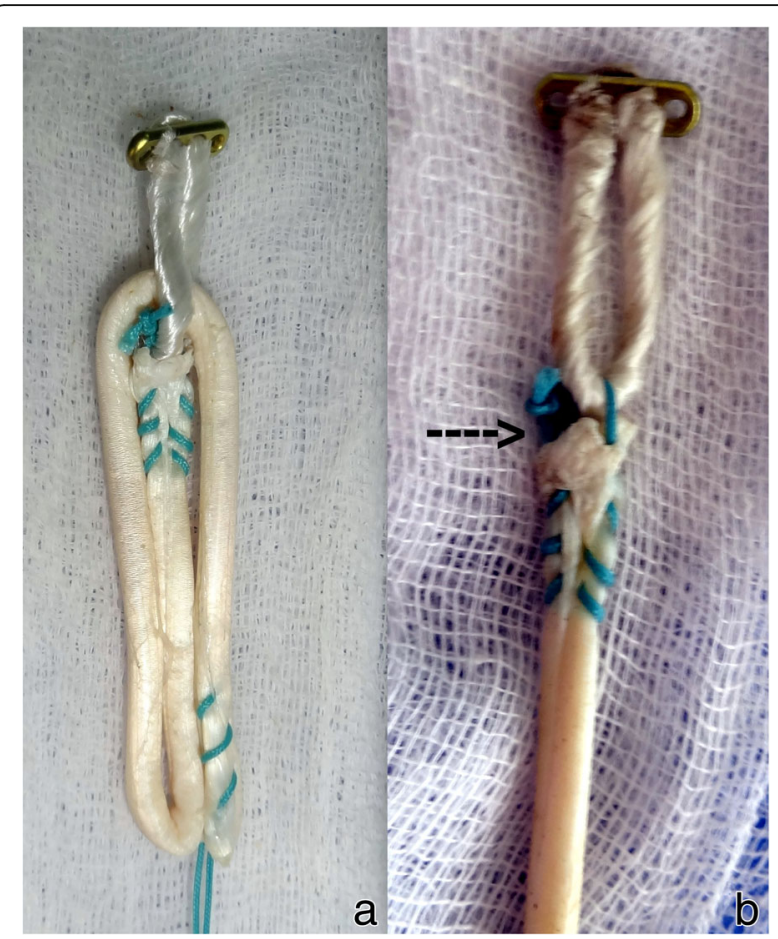

Fig. 7 Failure in Group II. a. Graft before mechanical testing. b. Graft after mechanical testing, arrow pointing to the site of loosening

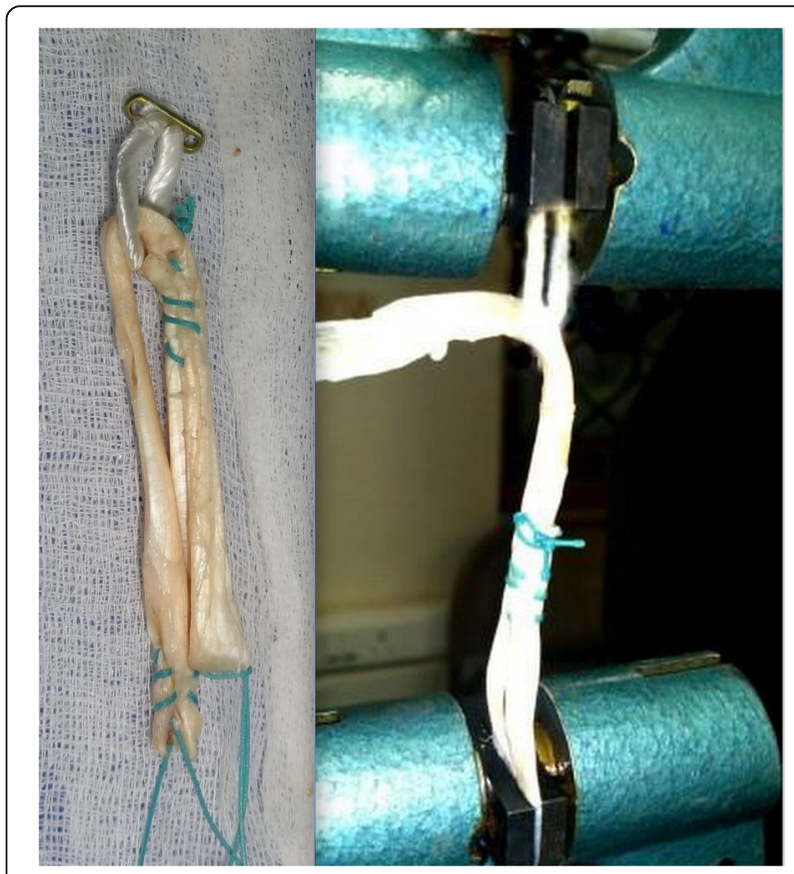

Fig. 8 Failure in Group III, Asymmetric loading and early rupture of tendon. (Representative figure) 
Table $1 \mathrm{Load}$ at failure and the mechanism of failure of all samples

\begin{tabular}{|c|c|c|c|c|c|c|}
\hline & Sample & Length $(\mathrm{cm})$ & Diameter $(\mathrm{mm})$ & Displacement (mm) & Load at Failure (N) & Mechanism of failure \\
\hline \multirow[t]{5}{*}{ Group I } & 1 & 8 & 8 & 1.22 & 948.06 & Tendon rupture \\
\hline & 2 & 8 & 8 & 1.16 & 966.97 & Tendon rupture \\
\hline & 3 & 8 & 8 & 1.07 & 1003.32 & Tendon rupture \\
\hline & 4 & 8 & 8 & 0.97 & 975.47 & Tendon rupture \\
\hline & 5 & 8 & 8 & 1.36 & 948.11 & Tendon rupture \\
\hline \multirow[t]{5}{*}{ Group ॥ } & 1 & 8 & 8 & 4.68 & 625.01 & Pull out of central tendon stitch \\
\hline & 2 & 8 & 8 & 4.49 & 586.65 & Pull out of central tendon stitch \\
\hline & 3 & 8 & 8 & 4.66 & 616.60 & Pull out of central tendon stitch \\
\hline & 4 & 8 & 8 & 4.99 & 581.14 & Pull out of central tendon stitch \\
\hline & 5 & 8 & 8 & 5.72 & 640.02 & Pull out of central tendon stitch \\
\hline \multirow[t]{5}{*}{ Group III } & 1 & 8 & 8 & 2.38 & 649.09 & Tendon slip on the loop and tendon rupture \\
\hline & 2 & 8 & 8 & 1.65 & 649.94 & Tendon slip on the loop and tendon rupture \\
\hline & 3 & 8 & 8 & 0.96 & 660.38 & Tendon slip on the loop and tendon rupture \\
\hline & 4 & 8 & 8 & 2.14 & 738.54 & Tendon slip on the loop and tendon rupture \\
\hline & 5 & 8 & 8 & 1.98 & 778.34 & Tendon slip on the loop and tendon rupture \\
\hline \multirow[t]{5}{*}{ Group IV } & 1 & 8 & 8 & 1.22 & 1008.72 & Tendon rupture \\
\hline & 2 & 8 & 8 & 0.93 & 957.42 & Tendon rupture \\
\hline & 3 & 8 & 8 & 1.15 & 968.76 & Tendon rupture \\
\hline & 4 & 8 & 8 & 0.97 & 957.20 & Tendon rupture \\
\hline & 5 & 8 & 8 & 1.36 & 981.28 & Tendon rupture - \\
\hline
\end{tabular}

anecdotal reports of their use (Figueroa et al. 2018; Krishna et al. 2018; Lee 2013; Strobel et al. 2011). Though both the groups III and IV had optimal displacement and load to failure values, there was significant difference in load to failure values between the two groups. Of the three constructs tested, only the Group IV, in which all three strands were tied together, near Endobutton CL loop, had equivalent mechanical properties as quadrupled grafts.

Samples in group II failed by pull out of whipstitch from the central tendon. Samples in the groups I, III, and IV failed by intratendinous stretch and rupture. The samples in group III behaved as doubled tendon graft, with asymmetric strands (Fig. 2). Consequently, the stresses in two strands are unequal, leading to early stretching and failure of one of the strands (Fig. 8). The samples in Group I and Group IV had no asymmetric

Table 2 Statistical analysis

\begin{tabular}{lllll}
\hline & Groups & Observed ' $t$ ' value & Table ' $t$ ' value & ' $p$ ' value \\
\hline Displacement & I Vs. I| & 16.92 & $3.355(p=0.01)$ & $p<0.01$ \\
& I Vs. III & 11.15 & $3.355(p=0.01)$ & $p<0.01$ \\
& I Vs. IV & 0.044 & $1.806(p=0.10)$ & $p>0.10$ \\
Load at failure & I Vs. I| & 24.27 & $3.355(p=0.01)$ & $p<0.01$ \\
& I Vs. III & 9.63 & $3.355(p=0.01)$ & $p<0.01$ \\
& I Vs. IV & 0.45 & $1.806(p=0.10)$ & $P>0.10$ \\
\hline
\end{tabular}

stress distribution and all the four or three strands, respectively, failed together. This was reflected in the failure loads noted with the four groups.

One limitation of our study is that we have not analysed the differential loading in each of the loop. Snow et al. have noted that the third limb of the tripled tendon undergoes cyclic elongation relative to the doubled portion of the grafts (Snow et al. 2012). Secondly, we have tested the longitudinal load to failure and this represents the extreme case scenario and forces placed on an in vivo graft are likely to be lesser magnitude. In the clinical setting, when the usually experienced forces may be lesser, the differences may not be clinically significant. Furthermore, unidirectional tensile testing to failure does not stimulate the true geometry and loading of the intact ACL. As the knee joint travels through its range of motion, the relative loading in the strands of the ACL and graft changes, and reproducing this was not possible in our study. The third limitation is that we used a clamp on the tibial side whereas in tibial fixation is commonly performed with interferential screw. Hence the mode of failure in clinical setting, when tibial fixation is performed with interferential screw or cortical fixation, may not be the same as noted in the laboratory. Furthermore, in a similar study, Snow et al. identified failure by pull out from the tibial tunnel and this occurred at approximately $565 \mathrm{~N}-601 \mathrm{~N}$. Historically, tibial fixation 
of ACL grafts has been considered the weak link of ACL reconstruction (Steiner et al. 1994). The fourth limitation is that we have studied only the load to failure and displacement. Other factors like stiffness, strain, and graft incorporation have not been studied.

We have studied only five samples in each group. The small number samples is a limitation of the study. However the uniform mode of failure in all samples in each group correlates with the statistical observations of the study.

This is only a laboratory study using bovine tendons, using mechanical simulation of worst case scenario following cruciate ligament reconstruction. Therefore, the conclusions that can be drawn are limited. A prospective clinical trial is required comparing these techniques with each other.

\section{Conclusions}

In this mechanical study, we found mechanical differences between the tripled tendons prepared by different methods. Notably, only one method of graft tripling - in which all three strands where sutured together near the loop of suspensory device, had are equivalent mechanical properties as quadrupled graft.

\section{Acknowledgments}

The authors thank Dr. Pasupathi Ph.D., for his assistance in performing this study and SITRA, Coimbatore, India, for provision of equipment and use of laboratory facilities.

\section{Funding}

The study was funded by authors.

\section{Availability of data and materials}

All data generated or analysed during this study are included in this published article.

\section{Authors' contributions}

IG prepared the samples, conducted the laboratory study and drafted the manuscript. SS prepared the samples and assisted drafting the manuscript. AV performed the statistical analysis. DVR conceived the study, participated in its design and helped draft the manuscript. All authors read and approved the final manuscript.

\section{Ethics approval and consent to participate}

Not applicable.

\section{Consent for publication}

Not applicable.

\section{Competing interests}

The authors declare that they have no competing interests.

\section{Publisher's Note}

Springer Nature remains neutral with regard to jurisdictional claims in published maps and institutional affiliations.

\section{Author details}

${ }^{1}$ Arthroscopy Centre, Trichy, GastroCare Hospital, 11th Cross East, Thillai Nagar, Thiruchirappalli, Tamil Nadu, India. ${ }^{2}$ Ortho One Orthopaedic Speciality Center, Coimbatore, Tamil Nadu, India.
Received: 1 October 2018 Accepted: 13 November 2018

Published online: 27 November 2018

\section{References}

Chambat P, Guier C, Sonnery-Cottet B, Fayard JM, Thaunat M (2013) The evolution of $A C L$ reconstruction over the last fifty years. Int Orthop 37(2): 181-186

Chechik O, Amar E, Khashan M, Lador R, Eyal G et al (2013) An international survey on anterior cruciate ligament reconstruction practices. Int Orthop 37(2):201-206

Daniel DM, Stone ML, Dobson BE, Fithian DC, Rossman DJ et al (1994) Fate of the ACL-injured patient. Am J Sports Med 22(5):632-644

Daniel DM, Stone ML, Sachs R, Malcom L (1985) Instrumented measurement of anterior knee laxity in patients with acute anterior cruciate ligament disruption. Am J Sports Med 13(6):401-407

Donahue TL, Gregersen C, Hull ML, Howell SM (2001) Comparison of viscoelastic, structural, and material properties of double-looped anterior cruciate ligament grafts made from bovine digital extensor and human hamstring tendons. J Biomech Eng 123(2):162-169

Ferretti A, Monaco E, Giannetti S, Caperna L, Luzon D et al (2011) A medium to long-term follow-up of $A C L$ reconstruction using double gracilis and semitendinosus grafts. Knee Surg Sports Traumatol Arthrosc 19(3):473-478

Figueroa F, Figueroa D, Espregueira-Mendes J (2018) Hamstring autograft size importance in anterior cruciate ligament repair surgery. EFORT Open Rev 3 : 93-97. https://doi.org/10.1302/2058-5241.3.170038

Gobbi A (2010) Single versus double hamstring tendon harvest for ACL reconstruction. Sports Med Arthrosc 18(1):15-19

Krishna L, Tan XY, Wong FKL, Toh SJ (2018) A 5-Strand hamstring autograft achieves outcomes comparable to those of a 4-Strand hamstring autograft with a graft diameter of $8 \mathrm{~mm}$ or more in anterior cruciate ligament reconstruction. Orthop J Sports Med 6(3):2325967118760815

Lee YH (2013) Comment on "Mechanical assessment of two different methods of tripling hamstring tendons when using suspensory fixation". Knee Surg Sports Traumatol Arthrosc 21(8):1949-1950

Magnussen RA, Lawrence JT, West RL, Toth AP, Taylor DC et al (2012) Graft size and patient age are predictors of early revision after anterior cruciate ligament reconstruction with hamstring autograft. Arthroscopy 28(4):526-531

Mariscalco MW, Flanigan DC, Mitchell J, Pedroza AD, Jones MH et al (2013) The influence of hamstring autograft size on patient-reported outcomes and risk of revision after anterior cruciate ligament reconstruction: a multicenter Orthopaedic outcomes network (MOON) cohort study. Arthroscopy 29(12):1948-1953

Morrison J (1970) The mechanics of the knee joint in relation to normal walking. J Biomech 3(1):51-61

Petre BM, Smith SD, Jansson KS, de Meijer PP, Hackett TR et al (2013) Femoral cortical suspension devices for soft tissue anterior cruciate ligament reconstruction: a comparative biomechanical study. Am J Sports Med 41(2):416-422

Shelburne KB, Pandy MG (1998) Determinants of cruciate-ligament loading during rehabilitation exercise. Clin Biomechanics 13(6):403-413

Shelburne KB, Pandy MG (2002) A dynamic model of the knee and lower limb for simulating rising movements. Comput Methods Biomech Biomed Engin 5(2):149-159

Shelburne KB, Pandy MG, Anderson FC, Torry MR (2004) Pattern of anterior cruciate ligament force in normal walking. J Biomech 37(6):797-805

Snaebjörnsson T, Hamrin Senorski E, Ayeni OR, Alentorn-Geli E, Krupic F et al (2017) Graft diameter as a predictor for revision anterior cruciate ligament reconstruction and KOOS and EQ-5D values: a cohort study from the Swedish National Knee Ligament Register Based on 2240 patients. Am J Sports Med 45(9):2092-2097

Snow M, Cheung W, Mahmud J, Evans S, Holt C et al (2012) Mechanical assessment of two different methods of tripling hamstring tendons when using suspensory fixation. Knee Surg Sports Traumatol Arthrosc 20(2):262-267

Steiner ME, Hecker AT, Brown CH Jr, Hayes WC (1994) Anterior cruciate ligament graft fixation. Comparison of hamstring and patellar tendon grafts. Am J Sports Med 22:240-246

Streich NA, Reichenbacher S, Barié A, Buchner M, Schmitt H (2013) Long-term outcome of anterior cruciate ligament reconstruction with an autologous four-strand semitendinosus tendon autograft. Int Orthop 37(2):279-284

Strobel S, Haslinger K, Heitzer C, Sehic M (2011) Tendon preparation for cruciate ligament reconstruction using the semitendinosus and gracilis tendon. Endo Press Tutlingen Germany:15-20 
Vinagre G, Kennedy NI, Chahla J, Cinque ME, Hussain ZB et al (2017) Hamstring graft preparation techniques for anterior cruciate ligament reconstruction. Arthroscopy Techniques 6(6):e2079-e2084 https://doi.org/10.1016/j.eats.2017.08.031

Westermann RW, Wolf BR, Elkins JM (2013) Effect of ACL reconstruction graft size on simulated lachman testing: a finite element analysis. lowa Orthop J 33:70-77

Zysk SP, Krüger A, Baur A, Veihelmann A, Refior HJ (2000) Tripled semitendinosus anterior cruciate ligament reconstruction with Endobutton fixation: a 2-3year follow-up study of 35 patients. Acta Orthop Scand 71(4):381-386

Submit your manuscript to a SpringerOpen ${ }^{\mathcal{O}}$ journal and benefit from:

- Convenient online submission

- Rigorous peer review

- Open access: articles freely available online

- High visibility within the field

- Retaining the copyright to your article

Submit your next manuscript at $\boldsymbol{\nabla}$ springeropen.com 